\title{
EchoGéo
}

$8 \mid 2009$

Moyen-Orient : conflits et mobilités dans un espace mondialisé

\section{Le pique-nique}

Ou l'éloge d'un bonheur ordinaire

\section{(2) OpenEdition \\ Journals}

\section{Édition électronique}

URL : https://journals.openedition.org/echogeo/11098

DOI : 10.4000/echogeo. 11098

ISSN : 1963-1197

\section{Éditeur}

Pôle de recherche pour l'organisation et la diffusion de l'information géographique (CNRS UMR 8586)

\section{Référence électronique}

«Le pique-nique », EchoGéo [En ligne], 8 | 2009, mis en ligne le 01 avril 2009, consulté le 31 juillet 2021. URL : http://journals.openedition.org/echogeo/11098; DOI : https://doi.org/10.4000/echogeo.11098

Ce document a été généré automatiquement le 31 juillet 2021.

EchoGéo est mis à disposition selon les termes de la licence Creative Commons Attribution - Pas d'Utilisation Commerciale - Pas de Modification 4.0 International (CC BY-NC-ND) 


\title{
Le pique-nique
}

\author{
ou l'éloge d'un bonheur ordinaire
}

Cet ouvrage collectif dirigé par Francine Barthe-Deloizy est le résultat d'une démarche collective (24 auteurs) associant des apports impromptus (appelés ici florilèges) à un corpus thématique, fruit d'une recherche entreprise dans le cadre d'un atelier organisé par l'Institut Français des Recherches Iraniennes (IFRI), les services d'actions culturelles de l'ambassade de France en Iran et le laboratoire ENEC de l'Université Paris 4 Sorbonne. Le livre entreprend la généalogie d'une pratique qui relève à la fois de la mode récente, dans ses aspects les plus transitoires, les plus éphémères, et de la tradition la plus ancienne. Généalogie du mot tout d'abord, puis définition des trajectoires possibles pour pister son extension à des sphères de plus

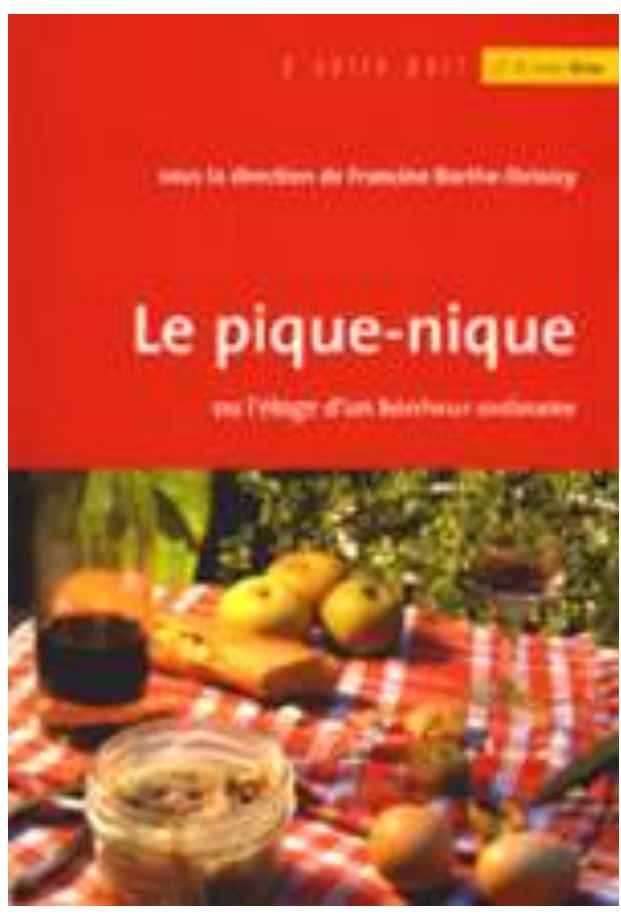
en plus diversifiées de culture.

2 Le pique-nique est une pratique ambivalente qui expose les éléments privés de l'intimité familiale recluse à la curiosité avide de l'espace public. Cet art de manger ensemble dehors développe, par compensation, des formes particulières de sociabilité où se lisent les différences et se vérifient les appartenances à telle classe sociale d'une époque donnée de l'histoire. Les personnalités géographiques des terroirs se dévoilent à la faveur d'une nappe déployée, à l'ombre ou au soleil, selon la saison, le temps d'une pause champêtre entre de durs travaux.

3 L'approche est à la fois généalogique et comparative, en cela qu'elle permet d'explorer les origines d'une pratique ancienne instituée en rituel codé, chargé de resserrer les liens sociaux et de transmettre les codes de l'organisation sociale par un système 
complexe de signes et de symboles. Selon la temporalité, le lieu retenu pour les retrouvailles, le nombre des personnes invitées et le niveau social, le pique-nique change de dimension et de portée. C'est ici que la géographie imprime le plus décisivement sa marque. La majorité des auteurs appartenant à cette discipline, leur démarche donne à la structure de l'ouvrage les aspects d'une grammaire des civilisations perçues à travers le prisme des pratiques culinaires associées au plein air.

L'ouvrage est divisé en trois parties et un florilège de souvenirs, dont chacun lève un coin de la nappe pour mettre en exergue un aspect particulier de la société.

La première partie tente la remontée aux sources d'une pratique attestée par des documents anciens. Des descriptions littéraires aux représentations artistiques de l'Antiquité, cette partie passe en revue les différentes évocations d'une pratique précocement répandue en Europe occidentale.

6 La deuxième partie est consacrée à la spécificité des terres de l'Islam où les repas pris en commun, autour d'un même plat, sont l'occasion de ressouder la communauté des croyants. Mais ici aussi, la diversité est la règle : que l'on soit Kurde, Berbère ou Arabe -, on ne s'expose pas de la même façon au vu de tous pour manger, le contenu du repas n'est pas le même, la préparation ne donne pas lieu aux mêmes partages de tâches entre les hommes et les femmes, les divertissements et les jeux associés au pique nique varient considérablement.

7 La troisième partie est l'occasion de développer plus en détail les éléments de sociabilité différenciée dans les pays européens dont chacun adopte dans le domaine du pique-nique des pratiques et des attitudes révélatrices des lignes de force de l'organisation sociale. Les festivités typiques des villes anglaises, les agapes champêtres des campagnes istriennes, les déjeuners sur l'herbe des immigrés turcs d'Allemagne sont l'occasion de vérifier l'ambivalence entre l'enracinement dans la tradition propre et l'ancrage dans des pratiques apprises par acculturation et assimilation en pays étranger.

Le florilège qui clôt cet ouvrage est l'occasion d'élargir le propos à des horizons plus diversifiés en donnant à voir comment, aux quatre coins de la nappe, les hommes se plient pour se passer le pain, le sel et les fruits de la terre avec une frugalité consommée et un sens aigu du partage.

Jean Marie Théodat

\section{BIBLIOGRAPHIE}

Le pique-nique. Ou l'éloge d'un bonheur ordinaire. Ouvrage collectif dirigé par Francine BartheDeloizy. Paris, Bréal, 2008. 256 pages. 